\title{
A Comparison of the Main Features of Suzuki and Traditional Violin Education
}

\author{
Hüseyin Bülent AKDENIZ \\ Anadolu University, Eskişehir, Turkey
}

\begin{abstract}
In early childhood education it is important to determine a child's ability or attitude towards different subjects. Training and/or education geared towards these tendencies will not only ensure a more healthy future choice in education for the child but furthermore will enable the child to have a happier educational atmosphere in early childhood. Music education/training in early childhood is considered to be very important in early years. Music education/training, in the correct and proper context using tangible and feasible teaching techniques not only improves and develops a child's musical skills but also helps develop his/her personality. Two people who shared this view were Zoltán Kodály and Shinichi Suzuki. Suzuki positively affected the educational systems worldwide with his approach to violin teaching and his ideas on early childhood pedagogy. Choosing between the Suzuki violin teaching methodology and the traditional violin teaching methodology is a personal decision. This article tries to objectively elaborate on different aspects of Suzuki and traditional violin teaching methodologies. Each methodology has its pros and cons and knowing what these are will help individuals to make a more educated choice.
\end{abstract}

Keywords: early childhood education, Suzuki, methodology, violin, music education, passive listening, handling the bow, traditional violin teaching methodology

\section{Introduction}

Music education and especially instrument education like in many other cases entail various techniques and approaches. The differences in these techniques and approaches also exist in early childhood education. The aim of this article is to objectively elaborate and discuss the features and distinctions of widely used traditional violin teaching methodology and Suzuki violin teaching methodology which became popular in the last century. The purpose of this paper is not to emphasize one over the other but to create awareness and inform the reader.

Suzuki violin teaching methodology in music education is commonly used in United States, Canada, Australia, Europe, and many other countries. It is a music education/training philosophy developed by Dr. Shinichi Suzuki and accepted by music trainers all over the world. It is also called "Skill Training" or "Native Language Methodology". Although it was initially developed to teach how to play the violin, it was then adapted for many instruments such as the piano, viola, cello, organ, and harp in addition to voice training and even mathematics, literature, and art education. 
Suzuki believed that by introducing discipline in education and by training good violinists it would be possible to build a peaceful society made up of responsible individuals and prevent wars. Fundamental aim of Suzuki trainers and parents whose children are in Suzuki training is not to create well-known soloists or musicians but to raise honest, capable, and principled individuals by providing children insight to ethical and humane values through music.

The current education/training systems were built on the belief that the musical skills are not innate but can be acquired by all children provided that suitable environmental conditions are maintained. According to Suzuki, children are born with the attitude of imitating everything that they see or hear around themselves. If the child's environment includes musical stimuli, the child not only develops his/her language skills but also has the chance of developing his/her musical skill.

Many have considered this methodology quite strange. Furthermore, there were diverse responses to Suzuki methodology from music trainers: "Suzuki methodology can only train child prodigies...", "Suzuki violin methodology is an imitation of other teaching approaches... Suzuki is the most natural way of learning how to play the violin...", "Suzuki methodology endangers the children's already existing skills...", "Rote learning decreases individuality in musical performance...".

The list goes on. Suzuki violin methodology advocates compare with traditional violin methodology advocates. Which one is more rational? How can the music trainers and parents decide which one to prefer in the presence of these conflicting messages? Understanding and comparing both methodologies can help with the decision process.

The purpose of this study is not to present an in-depth analysis of Suzuki and Traditional violin methodologies but to provide explanations and comparisons of some of the main features of these methodologies. It is expected that providing evaluation of different aspects will help practitioners, trainers, and parents.

\section{Suzuki's Philosophy of Education}

In the following the role of the teacher, parents, time span, musical training and the aspects of classroom training will be discussed.

\section{The Role of the Teacher}

In the Suzuki Method it is the teacher who decides which course materials to use. The teacher also introduces the musical instruments not only to the student but also to the parents. The teacher in all is responsible for all the teaching process. As Suzuki often stated that in native language acquisition musical training is an ongoing process. People parallels are drawn between first language acquisition and Suzuki, just like in the case of native language acquisition the learning process constantly evolves and therefore, teachers are responsible for enriching their teaching skills by continuously seeking new ideas and teaching techniques (Hongur, 2009a).

Suzuki teachers have to know Suzuki violin methodology as well as being conversant with the traditional violin methodology. Furthermore, Suzuki teachers are individuals who are "trained in teaching how to learn". These teachers are subject to a strict certification process.

\section{The Role of Parents}

Suzuki was well aware of the importance of the role of the environment in a child's development therefore, 
he put the family in the center of the child's music education. Parents receive information from the teacher about the basic features of what the instrument their child is playing and the teaching techniques employed. They even learn how to play the instrument themselves. Parents and the teacher are in constant contact and are helping each other and maintain a good communication for the well being of the student.

In Suzuki methodology, parents and teacher are real partners. Parents attend the lessons and carefully listen to the teacher's instructions. This participation enables them practice with their children and focus on their child's progress. Parents take the role of "home tutor". It provides an advantage to the student (Coff, 1998). After learning at school, in order cement what he/she has learned, the student continues to practice at home. In addition to developing the good relationship between the parents and the child compatibly, this situation fastens the learning process.

The reward of the participation of the parents in the process should be great as it demands so much time and self-devotion. While the family takes an active role in the musical education of their child they also take price and share the success of their child.

On the other hand, Traditional violin lessons are generally held in classroom without parents. Parents lack the advantage of helping their children. They could participate in their musical education nevertheless, they are outside participants rather than active ones. They generally listen to their children at concerts or recitals (Coff, 1998).

\section{Time}

Suzuki supports the idea that starting formal violin education at the age of two or three is very advantageous. He always thought that children can learn music like they learn how to walk or talk. The methodology developed by Suzuki and his colleagues, which is called "Skill Training Movement", is based on the idea that the best time to start violin education is the first years of a child's life (Coff, 1998). In addition to being quite suitable for young learners' musical education, Suzuki violin methodology is also proved to be effective for training the students of all ages (Estrella, 2005). Starting at an early age provides a well-established technical background.

Although the current learning approach focuses on children, it can be applied for the people of all ages who want to learn how to play the violin. On the other hand, traditional violin teachers rarely use their methodology to pre-primary school children who have interest or qualification. Generally, traditional violin teachers are chosen by the family of the child preferably starting by the primary school age (Coff, 1998).

\section{Passive Listening}

Every child has a perfect inborn ability to learn. Children can learn music and develop their retention capacity more easily by listening. Contrary to the traditional methodology which focuses on reading musical notation, Suzuki methodology makes children learn while playing. Starting from the works that will be studied and played at the beginning of the program, it is important to listen to the music which constitutes the repertoire of the instrument. This listening task is passive. Recordings at low volume are used as background music while the children are playing games. This listening process resembles the effect in natural language acquisition process. The success of the study is gained through continuous repetition of the listening. Students' musical performance increases as they memorize the music by internalizing the tone, timing and nuances of the music and recording the dynamics (Coff, 1998). An increase in the students' concentration and focusing is observed. Simultaneity of 
the song and game is surprisingly effective at increasing the children's self-confidence, performance and also his/her learning discipline.

In addition to emphasizing the importance of one-to-one tutors, Suzuki methodology supports doing group lessons and playing in groups once a week. Children like playing together and they get motivated by watching each other. They do not feel alone and develop a sense of security and trust (ozdemmusic.com).

Related studies indicate that the children who play an instrument learn collaboration, hand-eye coordination, develop their motor skills, and increase their spatial intelligence. Moreover, as the part of the brain which is for musical skills also develops mathematical skills, these etudes enable brain exercises for children and help develop mathematical skills of the children at the same time. In general, the children discovering theatre and musical instruments develop themselves socially, physically, emotionally, and academically (Berger, 2009).

As stated above Suzuki violin methodology is modeled after mother language acquisition and is paralleled in music education. A child listens more before speaking at early stages of his/her language acquisition and native language teachers do not teach reading right away, similarly, Suzuki teachers do not try to train technical particular of the instrument until their students accumulate enough of musical memory by playing games. As a result, students learn how to express music in a relaxed manner and fluently. Suzuki suggested that the students can learn and develop their technical ability more easily through teachers' leading them to peripheral learning while they are busy playing games (Coff, 1998). Like developing the basic language skills, children will develop a repertoire by listening to the music. Discovering the rhythm and playing the instrument are important pre-reading skills in serial learning.

Traditional violin studies almost always ignore peripheral learning. Students can be encouraged to listen to the advanced repertoire recordings by symphony orchestras or soloists; however, this is not done at the beginning of their learning process. Traditional violin teachers justifiably oppose memorizing and acquiring knowledge based on passive listening and they do not use this imitation technique even though they aim to develop new students' skills. In the memorization system of the traditional violin schools, memorizing the piece of music is ensured by repetitive reading of the work's notation.

\section{Violin Classrooms}

Suzuki violin classroom structure enables students to study together and share a common repertoire, their musical skills, and their aspirations. The concept of studying in a group is as important as the concept of one-to-one lesson. It is important to make the lessons more effective and satisfying by providing social interaction and giving chance to play in groups. This set-up also provides the opportunity to the children to observe their peers who are at different levels. It not only develops the concepts such as practicing together, collaboration, following the leader, but also directly affects the future career of the children in orchestra and chamber music.

On the other hand, traditional violin teachers generally use a classroom structure based on one-to-one lesson model. There is little or no opportunity to observe others' practice sessions. The lessons are conducted in an isolated environment. Competition among students is frequently used to motivate them. This could make the students more motivated or demotive them. In some cases, this kind of competition model could produce very selfish and aggressive future artists. Students do not have much chance to make music with their peers. 
Collaborative learning techniques are ignored. However, thanks to the recently developing technology, this firm stance has become more moderate.

In present times, some of the innovative thinking teachers promote and support the participation of others in their own classes and participation of famous violin trainers and virtuosos in master classes.

\section{Note Training}

According to Suzuki, if children learn to speak their native language before learning how to read, they can also learn to make music without knowing how to read musical notation.

Note training needs to start according to the age and skill of the child. This training should be given after the development of his/her musical sensitivity, playing skills, and memory skills. Reading musical notes is very important for a child; however, the child shouldn't be forced to learn the notes right at the beginning of the musical education program. Like in the first language acquisition, the child should start reading notes after learning how to play. Note training should provide the child the ability to play by heart. Playing by heart without using the notes will help the child to develop his/her memorization skills and learn quickly. If the child plays the works using notes, he/she will not be able to perform to his/her real ability level and develop his/her memory skills (ozdenmusic.com). Children become masters of their instruments before they learn how to read a musical note. In conclusion, they can focus on the music itself instead of the written symbols.

Note reading is highly important in Suzuki Methodology, too. The only thing that makes it different from traditional methods is when this training needs to start. In traditional violin schools, solemnization, note training, and theoretical education are given at the same time as violin playing instructions.

\section{Technique}

Suzuki adapted the education theories inspired by the approaches used in traditional Asian martial arts to music. This approach does not include the details and meticulousness. Suzuki formulated many impelling radical violin techniques. He developed a new style dominated by dramatic violin techniques (Coff, 1998).

It is possible to provide exercises to a new violinist in order to get a good tone from his violin. Both Paul Rolland and Dr. Michael Hopkins recommend "shadow bow" exercises. This exercise requires students to practice correct bow moves by using their shoulders or rolls of paper towels before the bow and the violin are played together. Rolland suggests performing the exercises which require placing the roll on the left shoulder in order to develop a proper forearm, wrist, and hand moves in bowing process. Students can apply these movements in their violin practices after they develop the proper forearm movements in "shadow bow" exercises (Nickel, 2009a).

The students using physical movements that they learned in "shadow bow" exercises, focus on practicing the proper arm movements while playing short music pieces. Students should adjust their metronomes for 60 beats per minute, which equals a crotchet. Then, the teacher should choose a piece of music which is well-known by the students and enable them to focus only on the bow movements and musical tone. After these practices students go on their exercises playing the piece of music by using longer tunes, double beating each note, and increasing the beat of each note. In order to increase the length of the each note, students will have to adjust the speed of the bow's movements, listen to the tonality, and focus on their arm movements (Nickel, 2009b).

In order to get a good musical tone, one should begin with holding the bow loose. All the fingers should be 
able to move at all points with each bowing process. Most students get wound up in two situations: thumb and little finger. Students frequently raise their little fingers while they are drawing their bows on the strings. For bow hold, Suzuki methodology recommends a circular shape for the hands and a flexible hand which will result with the least pressure on the bow (Nickel, 2009b).

When the students improve on holding the bow, they can succeed using larger part of the bow. Suzuki methodology recommends developing bowing by using bows at various lengths according to the pieces that will be played. He defined a series of physical movements so that the students can improve their tonality. The bow should be parallel to the threshold at all the points throughout the process of bowing. Natural movement-a suitable stance for the performance is necessary for effective but easy technique and rhythmic flow.

Traditional violin teaching is standard. Traditional studies can be detailed, demanding, and ambiguous in their teaching process.

\section{Musical Tuning}

Regardless of their age, all the new violin learners are sensitive to the tones of their instruments. Nevertheless, it is not easy for a novice to make a fine tone. Some exercises can help beginner violinists to get better sounds (Nickel, 2009a).

Making good musical tuning is necessary especially for beginner level violinists. Musical tuning motivates the musicians to practice more. They can learn smooth and proper playing moves and achieve a good musical tune with the simple exercises that they can do with their parents at home.

\section{Conclusion}

According to Suzuki philosophy, in the development process of children, they become self-confident, disciplined, talented, easily focused, collaborative, socially, physically, emotionally and academically developed and become sensitive individuals with advanced social skills who can appreciate art and music. Today, there are more than 400,000 Suzuki students all over the world.

As mentioned above, traditional violin teaching methods favor more conventional, individualized, and isolated training and thus promote a different personality in the musicians they train. While traditional methods acknowledge the priority of reading music notation, it is not possible to say that instrument education has strict and standard techniques. This methodology is centered on mentors and the musician is alone with the instructor as compared to Suzuki methodology. Students of traditional methodology do not know how to study in groups of orchestra or chamber music while learning to play the instrument, instead they learn to participate in groups as they go along and in time.

As mentioned at the beginning of this discussion, the purpose of the points put forward is not to promote one methodology over the other or make value judgments as to which one is better. In all areas where different teaching methods are used, there will be preferred techniques which are found more suitable by some teachers and learners. The important thing is to find the one which is useful and does not decrease the motivation of the students. Especially in music education, trainers have to determine which methodology will motive their students to handle their instrument again and again, encourage the students, and make them feel their own self-development. In this case, rather than stating that just traditional methodology or Suzuki methodology is the best, being able to use both traditional and Suzuki methods the best way is to put an eclectic approach forward by 
revealing the suitable techniques for the individual characteristics of the students.

Although Suzuki methodology and violin teaching methods bring diversity, innovation, and ease when compared to the traditional violin schools' violin teaching methods, traditional violin schools have trained and is training many successful musicians. Additionally, there are many traditional violin schools training good teachers and famous virtuosos too. All these issues should be taken into consideration and scrutinized when a teacher or a program for professional violin education is evaluated.

In conclusion, both Suzuki methodology and traditional methodology are effective to help children's development. While discussing these two methodologies, the thing that should be kept in mind is that both aim to develop the child and his/her character through music rather than to train fantastic musicians.

The role of the parents at the early ages of a child is key factor in the child's character and skills development. As Suzuki states, children's destiny is within the power of their parents. A happy childhood ensures a happy adulthood.

\section{References}

Berger, K. (2009). Group music lessons for young children. Retrieved January 2, 2011, from http://www.suite101.com/content/group-music-lessons-for-young-children-a137157

Coff, R. (1998). Suzuki violin vs traditional violin. Retrieved December 23, 2010, from http://www.suzuki-violin.com/suzuki_violin_vstraditionalviolin2.htm

Doman, S. (2010). Suzuki and colourstrings methods of teaching. Retrieved December 27, 2010, from

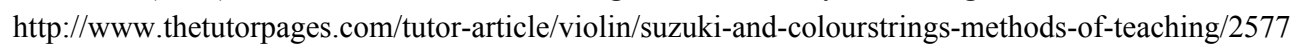

Estrella, E. (2005). Violin methods (Suzuki method). Retrieved January 2, 2011, from http://musiced.about.com/od/beginnersguide/a/vmethod.htm

Hongur, G. (2011a). Müzik Eğitiminde S.Suzuki ve Yetenek Eğitimi Felsefesi (Philosophy of talent education and S.Suzuki in $\begin{array}{lllll}\text { music } & \text { education). } & \text { January } & 3, & \text { 2011, }\end{array}$ http://gonenchongur.blogspot.com.tr/2008/09/mzik-eitiminde-shinichi-suzuki-ve.html

Hongur, G. (2011b). Suzuki Metodu (Suziki method). Retrieved January 3, 2011, from http://gonenchongur.blogspot.com.tr/2008/09/mzik-eitiminde-shinichi-suzuki-ve.html

Johnson, S. (1985). Young strings in action: Paul Rolland's approach to playing. Teacer's Book, 1(1), 8-13.

KinderU Suzuki Music Academy. (2010). About the Suzuki methodology. Retrieved December 28, 2010, from http://www.suzukihk.org/en_methodology.asp

Nickel, J. (2009a). Learn violin. $\quad$ Retrieved $\quad$ December $27, \quad 2010$, from http://www.suite101.com/content/learn-violin-a166899\#ixzz1Albosvlv

Nickel, J. (2009b). Violin lessons for kids. Retrieved December 27, 2010, from http://www.suite101.com/content/violin-lessons-a139345\#ixzz1Ald23K8S

Özdem Müzik. (2001). Keman Eğitiminde Suzuki Metodu (Suzuki method in violin education). Retrieved January 3, 2011, from http://www.ozdemmusic.com/icerik/342/keman-egitiminde-suzuki-metodu

Siow, P. (2011). Suzuki violin lessons versus normal violin lessons-What is better?. Retrieved January 2, 2011, from http://www.articlesnatch.com/Article/Suzuki-Violin-Lessons-Versus-Normal-Violin-Lessons---What-Is-Better-/958711\#ixzz 1BHOTKY6i

Suzuki Violin Teaching Points: Introduction. (2008). Retrieved December 27, 2010, from http://www.suzuki-violin.com/

Talent Education. (2005-2011). How does the Suzuki methodology differ from other methods?. Retrieved December 28, 2010, from $\mathrm{http}$ //www.talenteducation.org/index.php?option=com_content\&view $=$ article \&id $=65 \&$ Itemid $=82$

The Classical Music From Ace Zero. (2008). Retrieved December 27, 2010, from http://www.suzukimusicacademy.com/indexpage3.htm 